\title{
GAMBARAN TINGKAT DEPRESI PASIEN GAGAL GINJAL KRONIK YANG MENJALANI HEMODIALISIS
}

\author{
Abdul Wakhid ${ }^{1}$, Kamsidi ${ }^{1}$, Gipta Galih Widodo ${ }^{1}$ \\ ${ }^{1}$ Program Studi Keperawatan Universitas Ngudi Waluyo \\ abdul.wakhid2010@gmail.com
}

\begin{abstract}
ABSTRAK
Pasien yang menjalani hemodialisis sebagian besar ketergantungan terhadap mesin hemodialisis yang mengakibatkan terjadinya perubahan seperti masalah finansial, kesulitan dalam mempertahankan pekerjaan, dorongan seksual yang menghilang, impotensi, dan berisikomengalami depresi.Tujuan penelitian ini untuk mengetahui gambaran tingkat depresi pasien gagal ginjal kronik yang menjalani hemodialisis di RSUD Kabupaten Semarang. Desain penelitian yaitu deskriptif korelatif dengan pendekatansurvei. Populasi penelitian 85 pasien yang menderita gagal ginjal kronik yang menjalani hemodialisis.Teknik sampling menggunakan quota sampling sehingga jumlah sampel penelitian yaitu 85 pasien gagal ginjal kronik yang menjalani hemodialisis. Pengumpulan data menggunakan kuesioner tingkat depresi. Analisis data menggunakananalisisunivariat. Hasil penelitian diperoleh sebagian besar pasien gagal ginjal kronik yang menjalani hemodialisisdepresi ringan sejumlah 41 orang $(48,2 \%)$. Saran bagi RSUD Kabupaten Semarang untuk memberikan pelayanan keperawatan yang holistik pada pasien gagal ginjal kronik yang sedang menjalani hemodialisis.
\end{abstract}

Kata kunci: Tingkat depresi, gagal ginjal kronik, hemodialisis

\section{DESCRIBE DEPRESSION LEVEL OF CHRONIC KIDNEY FAILURE UNDERGOING HEMODIALYSIS}

\begin{abstract}
This research is motivated patients under going hemodialysis are largely dependent on hemodialysis machines resulting in changes such as financial problems, difficulty in keeping jobs, disappearing exualurges, impotence, and patient softenex perience self - conceptual disturbances as well as body image disturb ancesdue to the difficulty of accepting changes that result from failure kidney that experienced resulting in depressed patients. The research aim is to describe depression level of chronic kidney failure under going hemodialysis ar Semarang Regency hospital. This research used descriptive correlative method with cross sectional approach. Population in this research were $85 \%$ of patients with chronic renal failure who under went hemodialysis at RSUD Semarang Regency. Sampling technique used sample quota. Data collection questionnaires used depressi on level sand self concept questionnaires. Analysis univariat was used in this analysis. The results of the study show that most patients with chronic renal failure under going hemodialysis experience mild depression as many as 41 people (48.2\%). Suggestions to the hospital toteach patients to always optimistic to try new things, courageous, confident, enthusiastic, feeling self worth, dareto set a goal to live, behave and positively, and can be a reliable leader.
\end{abstract}

Keyword: Depression level, chronic kidney disease, hemodialysis

\section{PENDAHULUAN}

Pasien dengan gagal ginjal kronik sering kali mengalami perubahan, baik secara fisik maupun psikologis seperti, perasaan takut, cemas dan ketidakberdayaan.Selain itu, pasien sering kali mengalami gangguan konsep diri serta gangguan citra tubuh dan sulit menerima dirinya karena perubahan yang terjadi pada gagal ginjal (Morton, 2011). Seseorang yang mengalami suatu penyakit akan mengalami tahapan reaksi psikologis karena perubahan baik fisik maupun fungsi tersebut. Reaksi yang pertama yaitu pengingkaran, kemarahan, sikap tawar menawar (bargaining), penerimaan, dan yang terakhir adalah depresi(Kurniawati dan Nursalam, 2007). 
Prevalensi gagal ginjal kronik di dunia terutama di Amerika menurut United States Renal Data System (USRDS) pada tahun 2013 yaitu sekitar 650.000 kasus, dan pada tahun 2014 sekitar 651.000 kasus. Menurut Indonesian Renal Registry (IRR) prevalensi gagal ginjal di Indonesia pada tahun 2010 sebanyak 14.833 orang, pada tahun 2011 sebanyak 22.304 orang, dan meningkat pada tahun 2012 sebanyak 28.782 orang. Sedangkan menurut Perhimpunan Nefrologi Indonesia (Penefri) di Jawa Tengah pada tahun 2012 sebanyak 2.146 orang, pada tahun 2013 sebanyak 2.260 orang, dan meningkat pada tahun 2014 sebanyak 3.080 orang. Jadi kesimpulannya prevalensi gagal ginjal kronik tiap tahunnya meningkat baik di Dunia, di Indonesia, maupun di Jawa Tengah.

Berdasarkan data dari Riset Kesehatan Dasar (Riskesdas) tahun 2013 prevalensi gagal ginjal kronik di Indonesia dengan populasi umur $\geq 15$ tahun yang terdiagnosis gagal ginjal kronik sebesar 0,2\%. Angka ini lebih rendah dibandingkan prevalensi penyakit ginjal kronik di negara-negara lain, dan juga dengan hasil penyakit ginjal kronik sebesar 12,5\%. Sedangkan dengan tiap-tiap provinsi dengan prevalensi tertinggi di Sulawesi Tengah sebesar 0,5\%, diikuti Aceh, Gorontalo, dan Sulawesi Utara masing-masing 0,4\%. Sementara Nusa Tenggara Timur, Sulawesi Selatan, Lampung, Jawa Barat, Jawa Tengah, DI Yogyakarta, dan Jawa Timur masingmasing $0,3 \%$.

Hasil Riskesdas tahun 2013 menunjukkan prevalensi meningkat seiring dengan bertambahnya umur, dengan peningkatan tajam pada kelompok umur 35-44 tahun $(0,3 \%)$, diikuti umur $45-54$ tahun $(0,4 \%)$, dan umur 55-74 tahun (0,5\%), tertinggi pada kelompok umur $\geq 75$ tahun dengan $(0,6 \%)$. Prevalensi pada laki-laki $(0,3 \%)$ lebih tinggi dari perempuan $(0,2 \%)$, prevalensi lebih tinggi pada masyarakat perdesaan $(0,3)$, tidak bersekolah $(0,4 \%)$, pekerjaan wiraswasta, petani/nelayan/buruh $(0,3 \%)$, dan kuintil indeks kepemilikan terbawah dan menengah bahwa masing-masing (0,3\%).Pasien yang menjalani hemodialisis sebagian besar membutuhkan waktu terapi sebanyak 12-15 jam setiap minggunya, yang dibagi dalam tiga atau empat sesi dimana lamanya terapi berlangsung 3-4 jam (Alfiyan ti etal, 2014).Keadaan ketergantungan terhadap mesin hemodialisis mengakibatkan terjadinya perubahan dalam kehidupan penderita gagal ginjal terminal yang melakukan terapi hemodialisis.Perubahan yang terjadi seperti masalah finansial, kesulitan dalam mempertahankan pekerjaan, dorongan seksual yang menghilang serta impotensi, depresi akibat sakit yang kronis, perasaan kecewa dan putus asa, dan upaya untuk bunuh diri (Alfiyanti etal, 2014). Selain itu, perubahan gaya hidup terencana berhubungan dengan terapi dialisis dan pembatasan asupan makanan serta cairan menghilangkan semangat hidup pasien. Hal ini dapat menimbulkan permasalahan psikologis yaitu depresi pada pasien gagal ginjal kronik (Smletzer\& Bare, 2013).

Berdasarkan hasil wawancara dengan 5 orang pasien gagal ginjal kronik yang menjalani hemodialisis di RSUD Ambarawa, ditemukan 2 pasien memiliki kecenderungan mengalami depresi ringan, seperti memiliki perasaan tidak berharga, lebih suka berdiam diri di rumah dan merasa tidak berdaya. Pasien mengatakan bahwa merasa mengalamidepresi yang dialami sesuai keadaan dirinya sekarang, mereka tidak bisa melakukan aktivitas seperti biasanya dan selalu merasa merepotkan orang lain. Tidak pesimis menghadapi masa depan, tidak bisa tidur, nafsu makan berkurang, kehilangan minat.

Berdasarkan data yang di dapatkan dari hasil studi pendahuluan yang dilakukan di RSUD Kabupaten Semarang pada tanggal 7 november 2017 di RSUD Ambarawa, didapatkan hasil dari ruangan hemodialisis di RSUD Ambarawa untuk rata-rata jumlah kunjungan pasien hemodialisis kurang lebih 12-13 orang perhari. Dimana tiap pasien terjadwal menjalani hemodialisis 1-2 kali perminggu dengan durasi 3-4 jam sekali terapi.Tujuan penelitianiniuntuk mengetahuigambaran depresipadapasiengagal ginjal kronik yang menjalani hemodialisis di RSUD Kabupaten Semarang.

\section{METODE}

Desain penelitian yang digunakan dalam penelitian ini adalah deskriptif korelatif dengan pendekatan survei. Waktu penelitian dilakukan pada hari senin-rabu, tanggal 12-14 Februari 2018 dan pada hari senin-rabu, tanggal 19-21 bulan Februari 2018. Penelitian ini dilakukan di RSUD Kabupaten Semarang. Populasi dalam penelitian ini adalah pasien 
hemodialisissejumlah 85 sampel dengan menggunakan teknik sampling yaitu quota sampling Jenis data dalam penelitian ini adalah data primer. Peneliti melakukan pengambilan data dengan cara memberikankuesioner tingkat depresi. Analisis datamenggunakan analisis univariat yaitu analisis yang bertujuan untuk mendeskripsikan variabel depresidalam bentuk distribusi frekuensi dan persentase.

\section{HASIL}

Hasil penelitian dapat dilihat pada tabel berikut.

Tabel1.

Distribusi Frekuensi Berdasarkan Tingkat Depresi pada Pasien Gagal Ginjal Kronik yang Menjalani Hemodialisis $(\mathrm{n}=85)$

\begin{tabular}{lccc}
\hline \multicolumn{1}{c}{ Tingkat Depresi } & $\mathrm{f}$ & $\%$ \\
\hline Tidak Depresi & \multirow{2}{*}{ Ringan } & 41 & 16,5 \\
Depresi & & 30 & 48,2 \\
Depresi Sedang & & 35,3 \\
\hline
\end{tabular}

Berdasarkan tabel 1, diketahui bahwapasien gagal ginjal kronik yang menjalani hemodialisis di RSUD Kabupaten Semarang, sebagian besar mengalami depresi ringan, yaitu sejumlah 41 orang $(48,2 \%)$.

\section{PEMBAHASAN}

Hasil penelitian sebagaimana disajikan pada tabel 1 diketahui bahwa pasien gagal ginjal kronik yang menjalani hemodialisis di RSUD Kabupaten Semarang, menunjukkan bahwa sebagian besar pasien gagal ginjal kronik yang menjalani hemodialisis di RSUD Kabupaten Semarang mengalami depresi ringan yaitu sebanyak 41 pasien $(48,2 \%)$. Pasien yang mengalami depresi ringan akan kehilangan minat dan kegembiraan, berkurangnya energi dan akan mudah lelah yang membuat menurunnya aktivitas, konsentrasi dan perhatian kurang, harga diri dan kepercayaan diri yang kurang, dan hanya sedikit kesulitan dalam pekerjaan dan kegiatan sosial yang biasa dilakukannya.

Pasien yang mengalami depresi ringan adalah pasien yang memiliki tingkat pendidikan SMP dan SMA yaitu sebanyak 20 pasien $(39,2 \%)$ dan usia juga ikut mempengaruhi karena semakin bertambahnya usia pasien maka ada kecenderungan kecemasan pasien semakin menurun. Gangguan kecemasan dimulai pada awal masa dewasa, antara usia 15 dan 25 tahun, tetapi angka terus meningkat setelah usia 35 tahun ke atas seperti dalam penelitian ini dimana pasien sebagian besar berumur 5665 tahun yaitu sebanyak 46 pasien $(54,1 \%)$.

Hasil penelitian juga menunjukkan sebanyak 30 pasien $(35,5 \%)$ mengalami depresi sedang, hal tersebut dipengaruhi oleh faktor usia karena dari hasil data penelitian menunjukkan dari 30 pasien yang mengalami depresi sedang, 27 pasien $(90 \%)$ merupakan pasien dengan usia lansia akhir (55-65 tahun) dan 3 pasien (10\%) berusia manula (> 65 tahun).dan sebanyak 14 pasien gagal ginjal kronik $(16,5 \%)$ tidak depresi dalam menjalani hemodialisis di RSUD Kabupaten Semarang. Sedangkan 14 pasien (16,5\%) gagal ginjal kronik yang tidak depresi merupakan pasien dengan usia lansia awal (45-55 tahun) sebanyak 4 pasien $(13,3 \%)$, usia lansia akhir (56-65 tahun) sebanyak 8 pasien $(57,1 \%)$ dan 1 pasien $(7,1 \%)$ berusia manula (> 65 tahun).

Kemudian jenis kelamin juga turut serta mempengaruhi depresi pasien. Hal ini sebagaimana hasil penelitian bahwa dari 14 pasien $(16,5 \%)$ yang tidak mengalami depresi, 9 orang $(64,2 \%)$ merupakan pasien laki-laki, sedangkan 5 orang $(35,7 \%)$ merupakan pasien perempuan. Kemudian dari 30 pasien $(35,3 \%)$ yang mengalami depresi sedang, lebih banyak merupakan pasien perempuan yaitu sebanyak 12 pasien (40\%) dibandingkan pasien laki-laki yaitu sebanyak 15 pasien (50\%). Proporsi depresi yang lebih banyak terjadi pada perempuan dari pada laki-laki kemungkinan dikarenakan pada wanita terjadinya disregulasi sistem hormonal dan mengakibatkan aktivasi trombosit lebih besar sehingga mempengaruhi tingkat depresi pada wanita.

\section{SIMPULAN DAN SARAN Simpulan}

Sebagian besar pasien gagal ginjal kronik yang menjalani hemodialisis di RSUD Kabupaten Semarangmengalami depresi ringan yaitu sejumlah 41 orang $(48,2 \%)$.

\section{Saran}

1. Bagi Pasien Hemodialisis 
Pasienhemodialisistidak memandang dirinya sebagai pribadi yang rendah atau negatif, tetap semangat dan percaya diri, mampu mengatasi tekanan dalam kehidupannya, dan dapat lebih mensyukuri setiap perubahan yang terjadi pada dirinya sehingga terhindar dari kemungkinan terjadinya depresi.

2. Bagi Perawat

Diharapkan dapat memberikan konseling pada pasien gagal ginjal kronik sehingga pasien dapat memanajemen dirinya dalam menjalani hemodialisis.

3. Bagi RS Kabupaten Semarang

Disarankan kepada pihak rumah sakit untuk memberikan pelayanan keperawatan yang holistik pada pasien gagal ginjal kronik yang sedang menjalani hemodialisis, pola sosial-ekonomi, pola makan.

4. Bagi Institusi Pendidikan

Bagi institusi pendidikan diharapkan untuk memberikan pendidikan kepada mahasiswanya untukmengatasidepresi pada pasien gagal ginjal kronik agar mahasiswa dapat menerapkannya di lahan dan masyarakat.

5. Bagi Keluarga

Disarankan bagi keluarga untuk memberikan dukungan yang lebih kepada pasien, selalu memperhatikan keadaan pasien baik fisik maupun psikisnya, tidak mengeluh di hadapan pasien sehingga pasien merasa lebih nyaman, merasa tetap dihargai, dan diperhatikan sehingga dapat membantu pasien mengatasi atau menghadapi tekanan yang terjadi pada dirinya yang dapat memicu terjadinya depresi pada pasien.

6. Bagi Peneliti Selanjutnya

Bagi peneliti selanjutnya, diharapkan dapat melakukan penelitian lanjutan dengan meneliti faktor-faktor lain yang dapat mempengaruhi terjadinya depresi pada penderita gagal ginjal yang menjalani terapi hemodialisis, dan memperbanyak jumlah subjek penelitian, serta memperluas wilayah penelitian.

\section{DAFTAR PUSTAKA}

Alfiyanti, Nur Eva, Dody Setyawan, Muslim Argo, and Bayu Kusuma,2014. "Pengaruh Relaksasi Otot Progresif Terhadap Tingkat Depresi Pada Pasien Gagal Ginjal Kronik Yang Menjalani Hemodialisis Di Unit Hemodialisis RS Telogorejo Semarang."

Azahra M. Peran Konsep Diri dan Dukungan Sosial Terhadap Depresi pada Penderita Gagal Ginjal Yang Menjalani Terapi Hemodialisis. Jurnal Universitas Ahmad Daglan Yogyakarta. 2013;2(1)

Kurniawati, Ninuk D dan Nursalam, M. 2007. Asuhan Keperawatan Pada Pasien HIV/AIDS. Jakarta : Salemba Medika

Morton, Patrici, G. 2011. Keperawatan Kritis : Pendekatan Asuhan Holistik. Edisi 8. Bahasa Indonesia. Jakarta : EGC

PERNEFRI. (2012). $5^{\text {th }}$ Reportof Indonesian Renal Registry. Profil pasien hemodialisis di Indonesia.

Rikesdas. 2013. Laporan Nasional Riskesda $2013 . \quad$ http://litbag.depkes.go.id/. Diakses tanggal 01 oktober 2014

Smeltzer SC, Bare BG. Buku Ajar Keperawatan Medikal Bedah. Edisi. 12. Jakarta : EGC ;2015

Smeltzer SC, Bare BG. Buku Ajar Keperawatan Medikal Bedah. Vol. 2. Edisi. 8. Jakarta : EGC;2013 